\title{
Analyze EOR Potential of a Mature Oil Reservoir Using $\mathrm{CO}_{2}$
}

\author{
Hisham Khaled Ben Mahmud ${ }^{*}$, and Ian Chang Huan Sheng ${ }^{2}$ \\ ${ }^{1}$ Department of Petroleum Engineering, Curtin University, Sarawak, Malaysia \\ ${ }^{2}$ Sarawak Shell Berhad, Miri, Sarawak, Malaysia
}

\begin{abstract}
Enhanced Oil Recovery (EOR) is an approach of producing residual oil in depleted reservoirs. Carbon Dioxide $\left(\mathrm{CO}_{2}\right)$ injection is a promising method for EOR by increasing the reservoir pressure and also hydrocarbon displacement. $\mathrm{CO}_{2}$ injection has been widely used in oil industry as an effective technique for using $\mathrm{CO}_{2}$ is an optimization process that requires careful analysis. However, the objective of this project is to evaluate the application of $\mathrm{CO}_{2}$ injection as an enhanced oil recovery technique in sandstone reservoir and exploring possible improvement of oil production. An oil field located in South East Asia is considered in this study. The reservoir rock and fluid data were evaluated and implemented into Computer Modelling Group $(C M G)$ simulator where a synthetic simulation model is built for this process having injection and production wells. A model is developed to perform history matching with field production data to verify the model results and to perform a sensitivity analysis on cumulative oil production. The results show that the location, number and pressure of injector wells improve the reservoir performance with an additional oil recovery of 5\% OOIP, while injection rate has insignificant impact on the oil recovery with only $2 \%$ OOIP.
\end{abstract}

Keywords: Enhanced oil recovery, modeling, cumulative oil production, CMG, carbon dioxide.

\section{INTRODUCTION}

Improved oil recovery (IOR) is a technique of oil extraction, which assists in recovering further oil from mature oil fields via implementing different technologies. The majority of reservoirs are subjected to various IOR processes following the primary recovery such implementing horizontal production wells have shown improving and doubling the reservoir performance by a factor of 2 and reducing oil saturation from $80 \%$ to $30 \%$. (Hisham et. al. 2016). Enhanced oil recovery (EOR) is a method of oil extraction that assists in recovering additional oil from maturing oil fields via implementing different technologies. It is utilized to increase the amount of crude oil that can be extracted from the reservoir, apart from basic primary extraction methods and water flooding technique that can recover up to $20-60 \%$ of stock tank oil in place (STOIIP). If distinctive EOR methods are used to extract an oil, an additional 35-75\% of STOIIP can be generated from the reservoir. The major aim of EOR is to reduce the residual oil capacity and the operational expenditure, while maximizing the return on capital.

EOR technology has significantly increased in the last 20 years due to depleting reservoirs. It is a fact that approximately $70 \%$ of the oil \& gas production in the world comes from the matured oil fields; therefore, this numberindicates the potential for investments in EOR. Furthermore, the exploration rate of new fields has declined over the years due to several factors such as higher exploration cost, oil price collapse, etc. Therefore, the increase of oil recovery in the primary and secondary production phase will be crucial to meet the future energy demand (Alvarado, 2010). As the production from many mature fields in worldwide has declined and approached tail production, the operators have started to consider EOR as tertiary approach to increase the hydrocarbon recovery. $\mathrm{CO}_{2}$ technique is usually used after waterflooding in order to recover more hydrocarbon fluid and increase the field life span and profitability. Among various gas flooding processes, $\mathrm{CO}_{2}$ is much more preferred than other hydrocarbon gases due to its high displacement efficiency, high solubility in oil and lesser extent in water. Due to the high solubility, $\mathrm{CO}_{2}$ would reduce the crude oil's viscosity, while increasing the water's viscosity. These characteristics would also cause the crude oil to swell and reduce its density (Mathiassen, 2003). 
Moreover, $\mathrm{CO}_{2}$ achieves the miscibility at a pressure ranging from 100-300 bar, which is considered as a low pressure (Meyer, 2009). $\mathrm{CO}_{2}$ injection is suitable to be injected in sandstone or carbonate formations and the thickness can be in a wide range. For instances, some of the sandstone field studies in Malaysia have indicated that there is a potential of oil recovery (Taber, 1997). Many studies have shown that $\mathrm{CO}_{2}$ has become an excellent solvent for EOR where more than 80 projects of $\mathrm{CO}_{2}$ across USA and Canada have shown improving with an additional recovery of 7-15\% original oil in place (OOIP) (Mathiassen, 2003). The additional recovery using $\mathrm{CO}_{2}$ injection is in high demand from the industry as it will improve the project feasibility decision (Amao, 2009).

Zakirov et. al. (2012) studied water injection pattern schemes including horizontal, vertical, and deviated wells, and different well spacings were simulated to find the optimal water flooding patterns, and to evaluate different well trajectories. It found that the horizontal production wells show better performance compared to the deviated wells. Suman et. al. (2013) studied the efficiencies of different improved oil recovery strategies, ranging from water flooding to solvent injection. It does not include the effect of well placement, length of horizontal well or distance between producer and injector wells. It found that Water Alternating Gas (WAG) recovery process exhibits the greatest potential of optimizing recovery.

\subsection{Statement of Problem, Objective and Limitation of Study}

Since the majority of oil production has been produced from matured oil reservoirs using various EOR techniques, therefore; this indicator shows the potential of EOR approach to recover more oil from mature reservoirs, which many of them are currently operated at South East Asia for more than 30 years.

The main objective of this study is to evaluate the additional oil recovery by implementing $\mathrm{CO}_{2}$ as EOR method in a depleted sandstone oil reservoir in which a reservoir model was developed using history matching with field production data in order to verify the model results, and then a sensitivity analysis was conducted by altering different parameters including the location of injection wells, number of injection wells, injection pressure and injection rate. The study will not explain the effect of reducing $\mathrm{CO}_{2}$ emission and sequestration which can be stored into the reservoir upon flooding.

\section{MeThodology}

\subsection{Description of the Reservoir Model}

In this paper, a compositional simulation model was built using CMG GEM module (Version 2009.11, Computer Modelling Group Limited, Canada). The reservoir simulation model was 3Dimensional (3D) with a real field production history. The reservoir model consists of 3,500 grids, with grid blocks of $25 \times 35 \times 4$ and corresponding dimensions of $9022 \times 14354 \times 587 \mathrm{ft}$. Figure 1 displays the reservoir model used in this study in 3D.

The reservoir model is assumed to have homogeneous porosity and permeability in all directions where the average porosity is calculated to be $11 \%$ but each layer has its permeability value. The producer wells were positioned at the middle and right grid blocks as shown in Figure 1where the injector well was allocated at various locations to investigate its effect. The available data for the crude oil includes its composition, density, and viscosity are presented in Table 1.
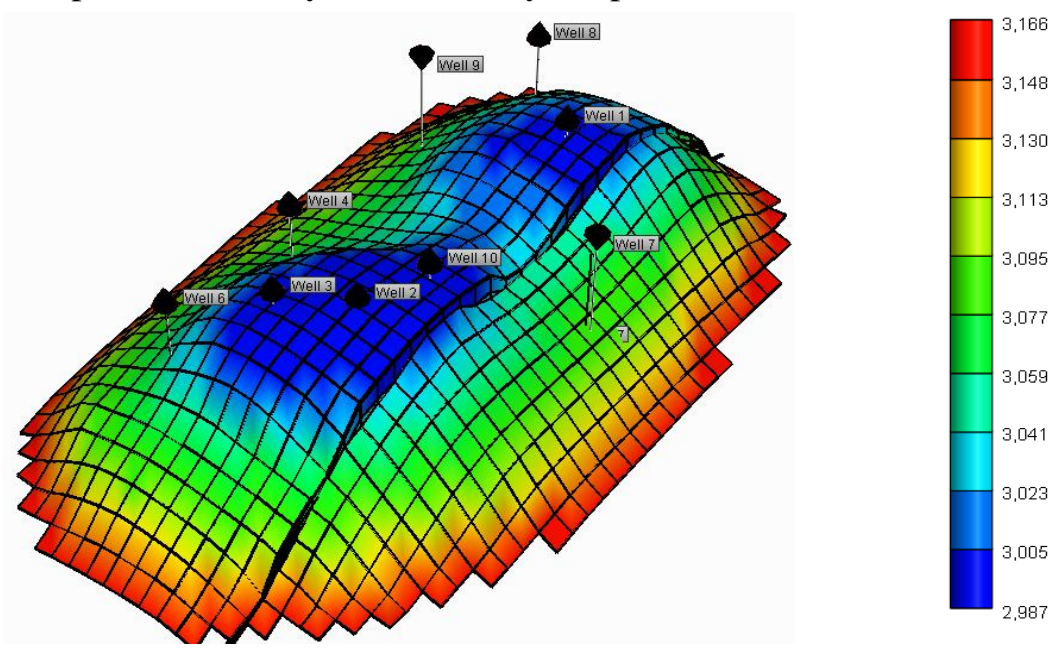

Figure1. 3-D grid model of an oil field with production and injection wells. 
The PVT model was constructed using CMG Winprop module (Version 2009.11) and tuned based on the available information. The model temperature in all the simulation runs was selected to be constant at $215^{\circ} \mathrm{F}$. The general properties of the simulation model are presented in Table 2 .

Table1. The composition of reservoir fluid

\begin{tabular}{|l|l|l|}
\hline Composition & Oil mole fraction & Gas mole fraction \\
\hline $\mathrm{H}_{2} \mathrm{~S}$ & 0.00 & 0.00 \\
\hline $\mathrm{CO}_{2}$ & 3.20 & 11.23 \\
\hline $\mathrm{N}_{2}$ & 0.00 & 0.50 \\
\hline $\mathrm{C}_{1}$ & 3.50 & 71.54 \\
\hline $\mathrm{C}_{2}$ & 1.50 & 10.20 \\
\hline $\mathrm{C}_{3}$ & 2.30 & 1.40 \\
\hline $\mathrm{i}-\mathrm{C}_{4}$ & 3.20 & 2.50 \\
\hline $\mathrm{n}-\mathrm{C}_{4}$ & 2.10 & 1.10 \\
\hline $\mathrm{i}-\mathrm{C}_{5}$ & 2.50 & 0.40 \\
\hline $\mathrm{n}-\mathrm{C}_{5}$ & 1.70 & 0.40 \\
\hline $\mathrm{C}_{6}$ & 3.50 & 0.43 \\
\hline $\mathrm{C}_{7+}$ & 76.50 & 0.30 \\
\hline
\end{tabular}

The aquifer layer is implemented underneath the oil layer using data related to the aquifer system into GEM simulator. This statement has supported by the high water cut of $40 \%$ at the initial production period of nine months as shown in (Figure 2).Also it can be seen that the water cut reaches almost $80 \%$ in 1998, which indicates the reservoir is supported by a strong water aquifer, therefore; this reservoir is classified as water drive mechanism where an additional material balance calculation is done to confirm the theory (refer to Appendix A). Moreover, no flow boundary conditions were assumed at the boundaries surrounding the reservoir in which reservoir edges could also be considered as a constant pressure boundary, however; there is no information along the boundaries of the reservoir.

\section{History MATCHING}

A history matching run was used to verify simulation data with the field data. Oil rate and cumulative water production data were matched simultaneously on the four production

wells named Well 2, 6, 8 and 10 using the oil rate as a controlling parameter. Figure 3 and Figure 4 (refer to Appendix B) show the final results of history matching for the simulated monthly oil and water production rate well data. The oil water relative permeability data was obtained at the end of the history matching study by a trial and error process. No liquid and gas relative permeability data were present. Thus, a gas relative permeability curve was generated by CMG's GEM corresponding relative permeability generation tool. The relative permeability curves of gas and water incorporated in the simulation model are shown in (Figure 5). It was assumed that the curves are the same for drainage and imbibitions. The capillary pressure among the oil, water and $\mathrm{CO}_{2}$ were neglected for this study.

Table2. Reservoir model and fluid properties

\begin{tabular}{|c|c|c|}
\hline Properties & \multicolumn{2}{|c|}{ Value } \\
\hline Average Length (ft) & \multicolumn{2}{|c|}{9022} \\
\hline Average Width (ft) & \multicolumn{2}{|c|}{14354} \\
\hline Average Thickness (ft) & \multicolumn{2}{|c|}{587} \\
\hline \multirow[t]{4}{*}{ Permeability (md) } & Layer 1 & 0.1 \\
\hline & Layer 2 & 20 \\
\hline & Layer 3 & 700 \\
\hline & Layer 4 & 100 \\
\hline Vertical to Horizontal Permeability Ratio $\left(\mathrm{K}_{\mathrm{v}} / \mathrm{K}_{\mathrm{h}}\right)$ & \multicolumn{2}{|c|}{0.9} \\
\hline Reservoir Bulk Volume, $\mathrm{V}_{\mathrm{b}}\left(\mathrm{ft}^{3}\right)$ & \multicolumn{2}{|c|}{$11.99 \times 10^{9}$} \\
\hline Average Porosity, $\phi$ & \multicolumn{2}{|c|}{0.11} \\
\hline Reservoir Pore Volume, $\mathrm{PV}\left(\mathrm{ft}^{3}\right)$ & \multicolumn{2}{|c|}{$1.62 \times 10^{9}$} \\
\hline Connact Water Saturation, $S_{w c}$ & \multicolumn{2}{|c|}{0.2} \\
\hline Initial Reservoir Pressure, $\mathrm{P}_{\mathrm{i}}(\mathrm{psi})$ & \multicolumn{2}{|c|}{4059} \\
\hline Top of Reservoir $(\mathrm{ft})$ & \multicolumn{2}{|c|}{9770} \\
\hline Reservoir Temperature $\left({ }^{\circ} \mathrm{F}\right)$ & \multicolumn{2}{|c|}{215} \\
\hline
\end{tabular}




\begin{tabular}{|c|c|}
\hline Rock Compressibility $\left(\mathrm{psi}^{-1}\right)$ & $1.38 \times 10^{-4}$ \\
\hline Critical Water Saturation & 0.2 \\
\hline Residual Oil for Water-Oil Table & 0.4 \\
\hline Residual Oil for Gas-Liquid Table & 0.2 \\
\hline Crude oil density $\left(\mathrm{kg} / \mathrm{m}^{3}\right)$ & 865 \\
\hline API gravity & $32^{\circ}$ API \\
\hline
\end{tabular}

\section{IMPROVED OIL RECOVERY (IOR) METHOD}

In this study, the reservoir was simulated to be depleted naturally. In the normal scenario, when the reservoir is unable to produce by the natural energy, water flooding is introduced to recover the oil, till the producer well is shut-in at the economic constraint. However, the condition of this reservoir is different from the usual case due to the presence of a strong water aquifer, which is characterized as water drive reservoir. Hence, the reservoir pressure is maintained by the aquifer and water injection would not have significant impact on the oil production.

As seen in (Figure 6), the water injection has not improved significantly the reservoir performance due to aquifer presence. On the other hand, the oil saturation in the reservoir is still remaining at high level after ten years of production as shown in (Figure 8-a) due to the presence of heavy oil fluid. The consequence of heavy oil properties, it prevents the flow of oil towards the production wells. Therefore, the reservoir is still at the state of initial oil saturation conditions of $80 \%$. Moreover, the oil saturation seen only decreasing around the vertical production wells, while the production from the reservoir boundary is not withdrawn towards existing production wells. Therefore, in order to improve the oil recovery in the secondary stage, two horizontal wells were drilled to increase the contact area with the reservoir in order to maximise the production.

As two horizontal wells were drilled after one year of nine months of production history with 3 months' interval between two wells to provide a sufficient time for the drilling to take place. The location of two horizontal wellsis shown in (Figure 8-b). The injector and horizontal wells were drilled in the layer 2 instead of other layers due to the high permeability ratio $(\mathrm{Kv} / \mathrm{Kh})$ of 0.9 andall reservoir layers arein communication with each other. Therefore, the oil from layer 4 is able to flow into the horizontal wells with the aid of gravity forces. However, layer 1 was not chosen due to the low permeability ratio of $0.1 \mathrm{md}$, which indicates a shale formation.

The result of drilling two horizontal wells shows a significant impact on the oil production where the oil recovery increased to $35 \%$ as presented in (Figure 8). Hence, the production was doubled the existing recovery of $18 \%$ due to the additional horizontal wells. From (Figure 6), the cumulative oil of $27 \mathrm{MMbbl}$ was achieved at 2006 where the horizontal wells were drilled, while the profit of the oil recovery is equivalent to $\$ 1.35$ billion US dollar if the oil price is $\$ 50$ dollar per barrel.

Therefore, the drilling cost of two horizontal wells will be covered, and a high profit can be obtained. After two horizontal wells were drilled, the oil saturation is reduced to between $30-50 \%$ as shown in (Figure 8-b). Therefore, as the reservoir approaches the tail of natural drive production and the remaining saturations have to be produced using EOR method, where $\mathrm{CO}_{2}$ injection is selected as EOR technique in this research.

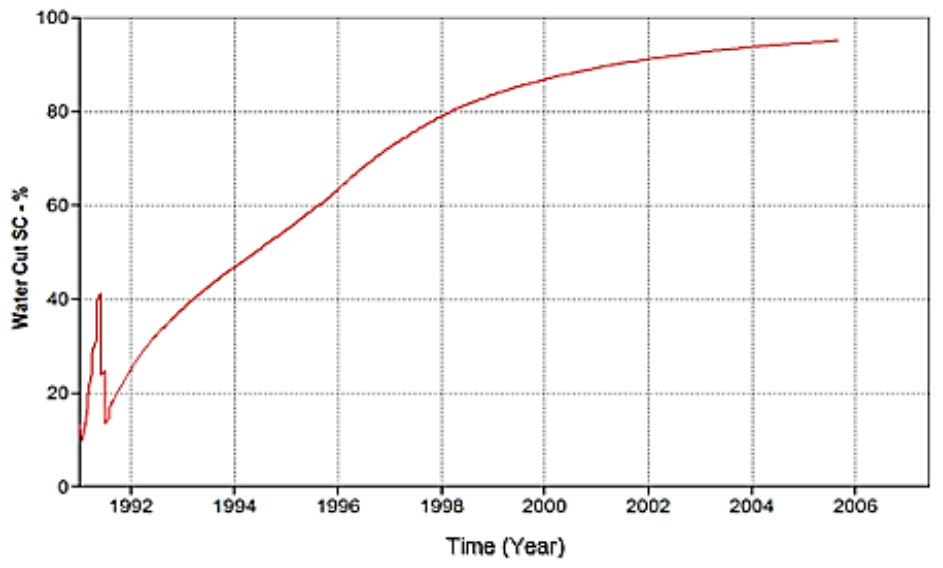


Figure2.Water cut percentage in the reservoir.
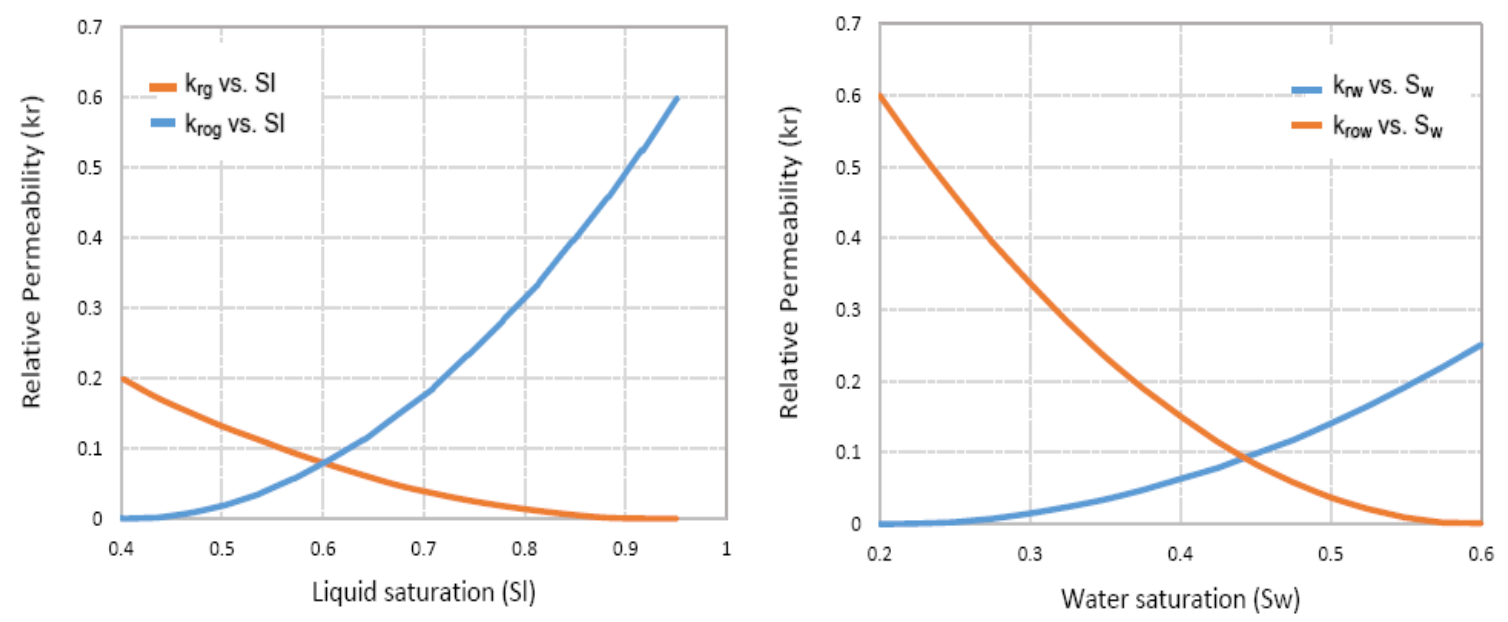

Figure5. Relative permeability of (a) oil-gas system and (b) oil-water system.

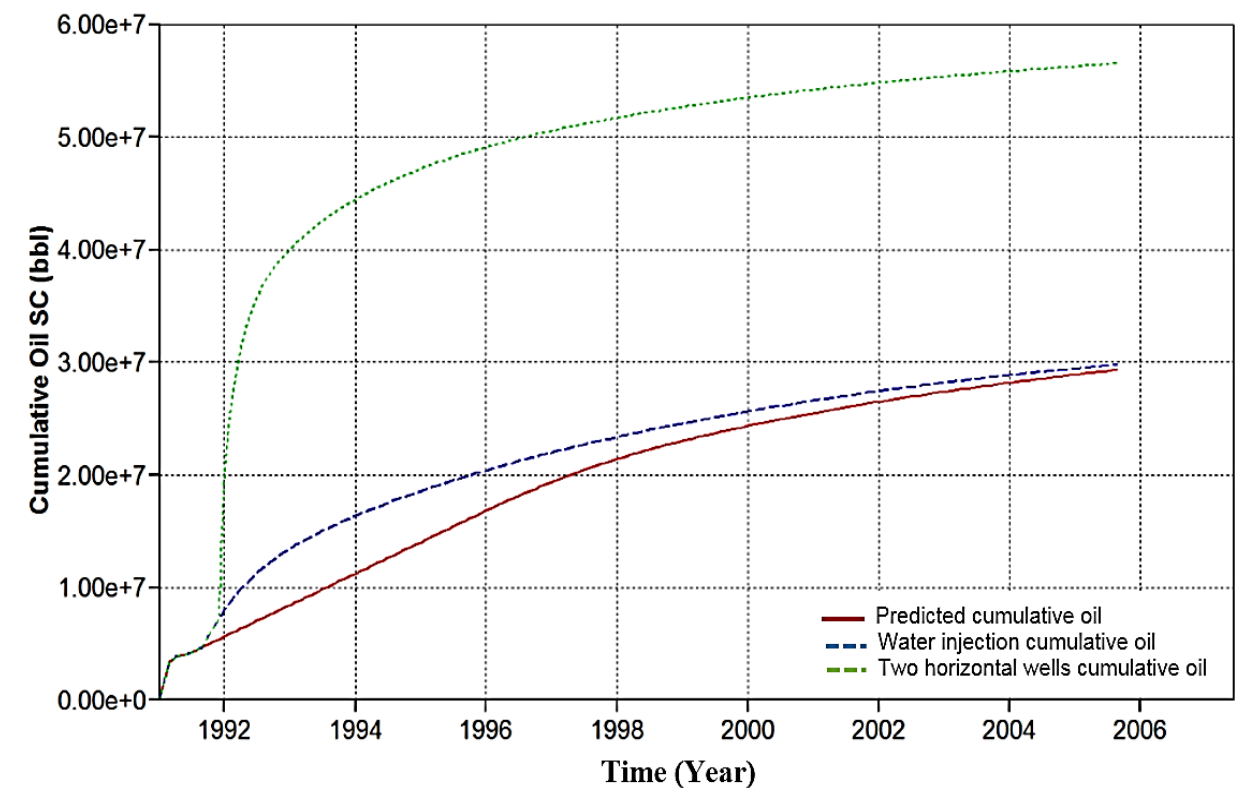

Figure6. Cumulative oil using improved oil recovery approaches.

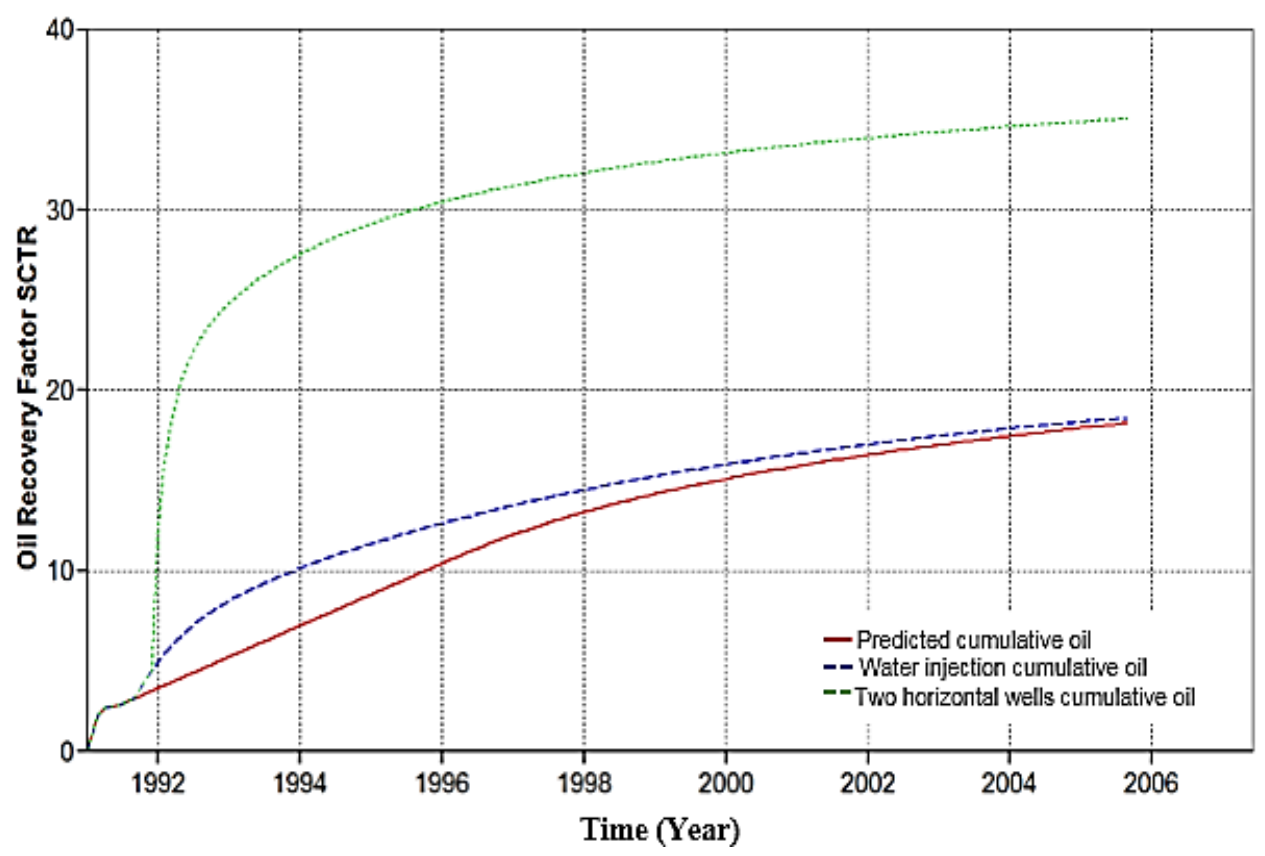


Figure7. Oil recovery factor using improved oil recovery approaches.
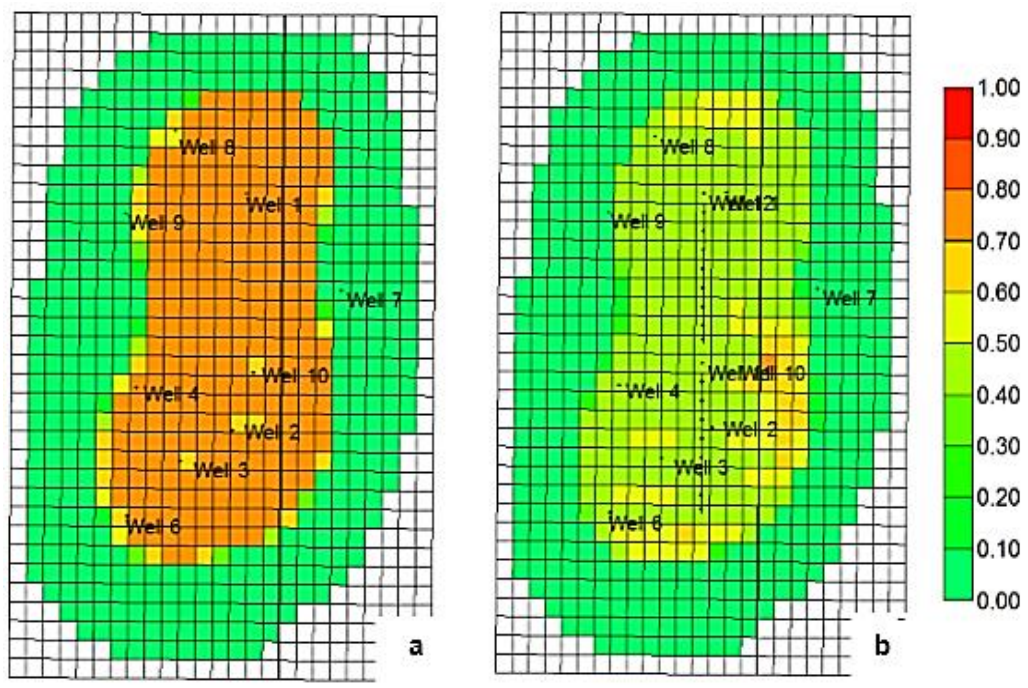

Figure8. Oil Saturations: (a) after nine months of production and (b)after two horizontal wells drilled.

\section{Simulation Sensitivity STUdies}

The oil behaviour of A-16 field was examined in different simulation scenarios. Different factors were investigated and analyzed to determine the optimum value and the highest oil recovery rate. Figure 1 presents the location of all production and injection wells for the following runs.

\subsection{Run 1: Starting Injection Time of $\mathrm{CO2}$}

After the improved oil recovery stage that showed a slightly improvement on cumulative oil and recovery factor.The next stage is to conduct enhanced oil recovery (EOR) approach in which $\mathrm{CO}_{2}$ injection was selected for this study due to its characteristics that mentioned earlier. Therefore, this section will study the best starting period of gas injection for the effective displacement of oil reservoir. $\mathrm{CO}_{2}$ gas was injected into the reservoir at the south location where most of the producer wells are located. The IOR method was introduced in Jan 1992. Therefore, the injection was initiated after three months and ten years of introducing IOR, March 1992 and Jan 2002. The cumulative oil production results of different injection starting periods are shown in (Figure 9). The purple curve indicates the prediction of cumulative oil if there is no IOR or EOR method applied.

Moreover, it was observed that both the early and late stage of injection had equally increased in the oil production $(5 \mathrm{MMbbl})$ until it reached the economical limit where the abandonment pressurewas set to $10 \mathrm{MPa}$. The result shows that cumulative production of the injection on the late period (10 years) had a higher cumulative production than the early period of injection ( 3 months) towards the end life of the reservoir. Moreover, the additional oil recovery factor increased by $4 \%$ on the late stage of injection compared to the early stage where the additional oil recovery is only $1 \%$ as shown in (Figure 10).

Therefore, the overall field oil recovery is significantly impacted when the injection was started after ten years. However, from the water cut result shown in (Figure 11), it can be observed that the water cut reached $80 \%$ in 3 months after the two horizontal wells were drilled. As a result, the field reached the economic constraint of $80 \%$ water cut of total production and the production wells are expected to be shut in after the $80 \%$ of water cut has reached, which is the economic limit. It can be concluded that the best starting period for $\mathrm{CO}_{2}$ injection is 3months after applying IOR scheme.

\subsection{Run 2: Effect of Injection Well Location}

In this section, the location of injection well was chosen as a parameter to determine the effect of different injection well sites in the reservoir to evaluate the additional cumulative oil and recovery, whereby different spots of injection pattern were studied. The injection well location was chosen and modelled at various places north, south and middle. The injection location was altered with the fixed injection pressure and injection rate at $30 \mathrm{MPa}$ and $30,000 \mathrm{~m}^{3}$, respectively. The purpose is to ensure consistent analysis through various locations since these parameters are sensitive to the reservoir performance. Moreover, the number of injection well was fixed with one well at each location. 
In addition, the injection starting period was fixed to March 1992 for all cases as concluded in previous Run 1. The north, south and middle location of the injection wells indicated via (INJ Well) as seen in (Figures 12). $\mathrm{CO}_{2}$ was injected in few layers 2, 3 and 4 but not layer 1 as expected a shale formation. Moreover, the middle location of injection well was drilled $100 \mathrm{~m}$ away from the fault to avoid any issues during the drilling and may reactivate the fault. The results of cumulative oil production from each location were shown in (Figure 13), where the cumulative oil production was plotted against time in year.

From the oil saturations results shown in (Figure 12), it was observed that injecting $\mathrm{CO}_{2}$ gas shows miscible reaction with the crude oil and reduces the oil saturation up to $10 \%$. Moreover, this indicates that $\mathrm{CO}_{2}$ injection was able to reduce the oil viscosity, and therefore, reduces the surface tension of oil and water, resulting in a more effective displacement. The result of cumulative oil production in (Figure 13) shows that the south location is the best spot for injection. Furthermore, the additional oil recovery factor in the south location is determined to be $4 \%$ as shown in (Figure 14). The increasing cumulative oil production is due to the presence of numerous well producers in the south location compared to other location. Therefore, this location enhances the oil recovery in efficient manner as more producers were impacted by the effect of $\mathrm{CO}_{2}$ injection. The south location had injection pattern of 7-spot with a distance of 100 to $800 \mathrm{~m}$ in which one injector and six producers are available in the location. The 7-spot injection pattern was observed from (Figure 12-c) where it shows the impact of $\mathrm{CO}_{2}$ injection on the oil saturations in a particular area. On the other, the middle location had only 3spot injection pattern where only two horizontal production wells were impacted by the injector; whereas the top (North) location had 4-spot injection pattern where three production wells were impacted by one injector.

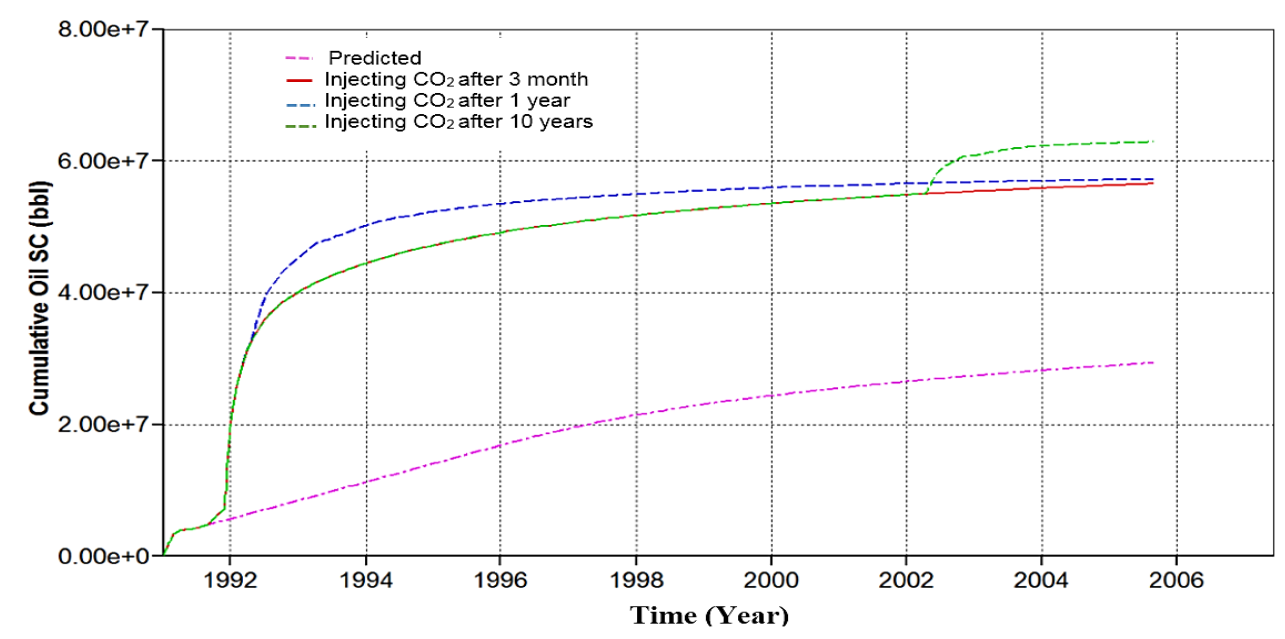

Figure9. Cumulative oil production of $\mathrm{CO}_{2}$ injection starting period

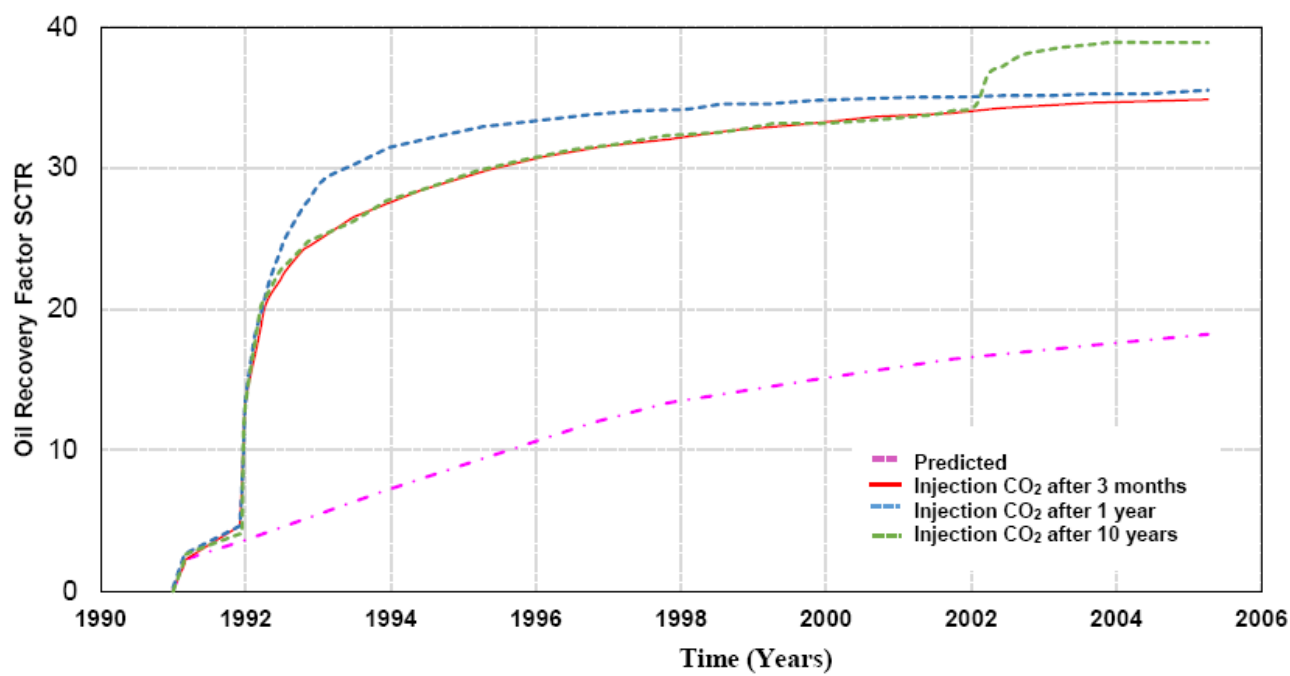

Figure10. Recovery Factors of various Injection Starting Periods. 


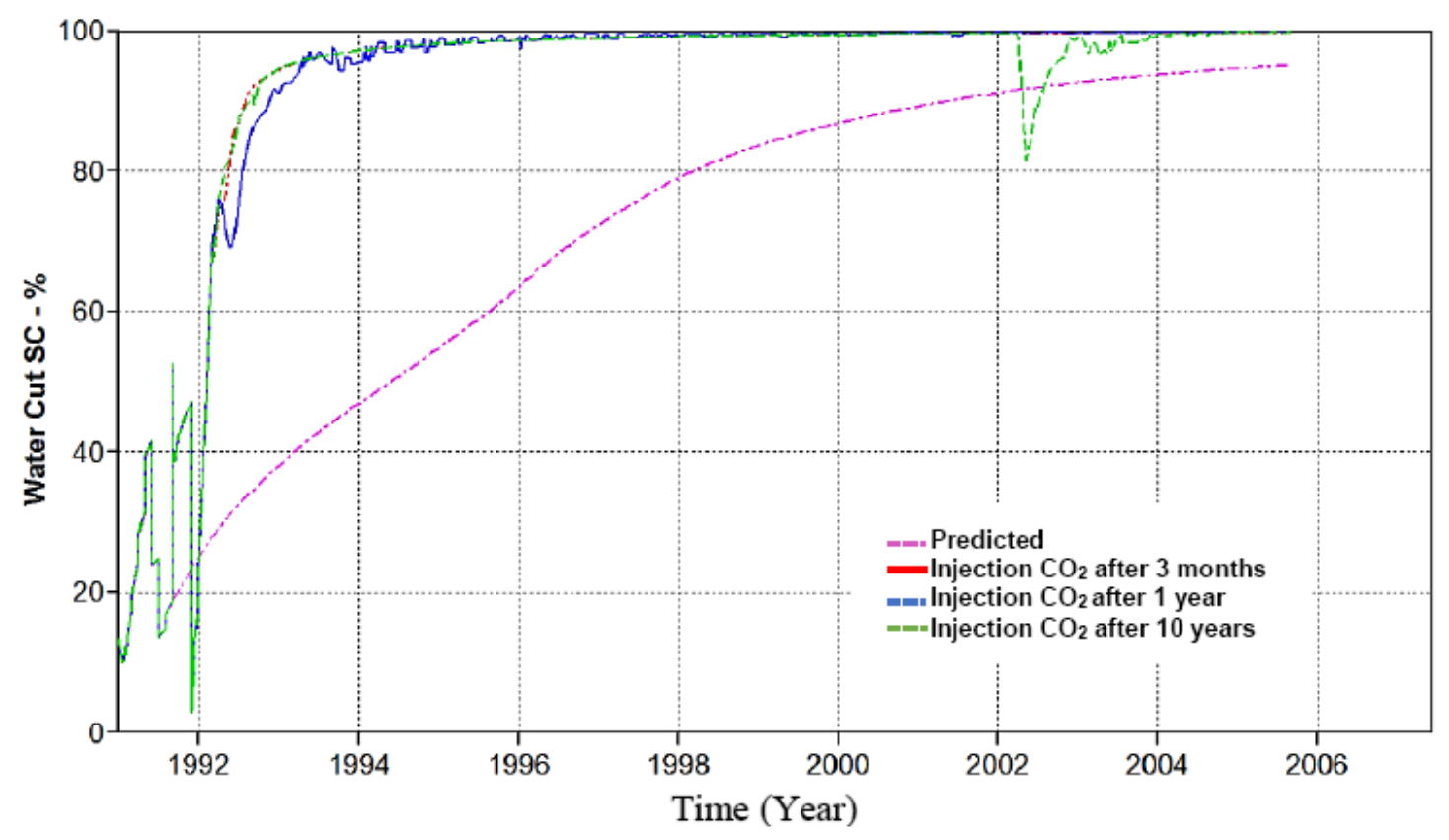

Figure11. Water cut of various injection starting periods

However, the middle and top locations had less a cumulative production even lower than the predicted production without EOR concept. This is due to the effect of viscous fingering and gravity tonguing, which caused by the relatively low oil density and viscosity and gaseous form of $\mathrm{CO}_{2}$ injected. Viscous fingering takes place when the gaseous $\mathrm{CO}_{2}$ by pass the oil and flow into the production well. Therefore, this causes the reservoir pressure to be blown off and thus, the production would reach to the abandonment pressure sooner than planned.

Moreover, viscous fingering effect is more severe when in contact with the horizontal well due to large contact area. Hence, $\mathrm{CO}_{2}$ gas will escape into the horizontal production well more easily. Therefore, in order to avoid this negative impact, some suggestions listed below can be prepared to improve the sweep efficiency:

- Shutting in production wells for a period of time to regulate the flow.

- Adding foam solution together with $\mathrm{CO}_{2}$.

- Installation of well packers and select a prober perforation technique.

Furthermore, the volumetric sweep efficiency can be significantly improved by implementation of Water Alternating $\mathrm{CO}_{2}$ (WAG) in which gas mobility in the reservoir can be reduced and becomes closer to the mobility of water. However, the effect of hysteresis on relative permeability's in drainage and imbibitions has to be taken into account. In addition, it is important to find the optimal ratio of water/ $\mathrm{CO}_{2}$.

\subsection{Run 3: Effect Of injection Well Number}

In this scenario, the number of injection well is used as a parameter to determine the reservoir production and performance where the south location was selected from previous scenario of sensitivity analysis and the injector well was increased one by one in the same location with a fixed injection pressure and rate of $30 \mathrm{MPa}$ and $30,000 \mathrm{~m}^{3}$, respectively. Therefore, three simulation runs with different number of injection wells were conducted and the results of cumulative oil production are shown in (Figure 15). The obtained result illustrates that before 1993, it was seen that using two and three injection wells had a higher cumulative oil production (45 $\mathrm{MM} \mathrm{bbl}$ ) compared to one injection well (42 MMbbl).

Moreover, the production wells reached the abandon pressure (10 MPa) at 1995, and thus, the curve shows a straight line. From the simulations results (Figure 16) also it was observed that one injection well had the best overall performance of oil recovery compared to two and three injection wells, which shows an additional oil recovery of 5\% in the early stages of the production. Therefore, it is deduced that the $\mathrm{CO}_{2}$ gas had poor macroscopic sweep efficiency and $\mathrm{CO}_{2}$ gas had breakthrough the 


\section{Hisham Khaled Ben Mahmud \& Ian Chang Huan Sheng}

oil in the early dates of EOR production. This situation is caused by the effect of viscous fingering as a result of the presence of heavy oil and gaseous $\mathrm{CO}_{2}$.
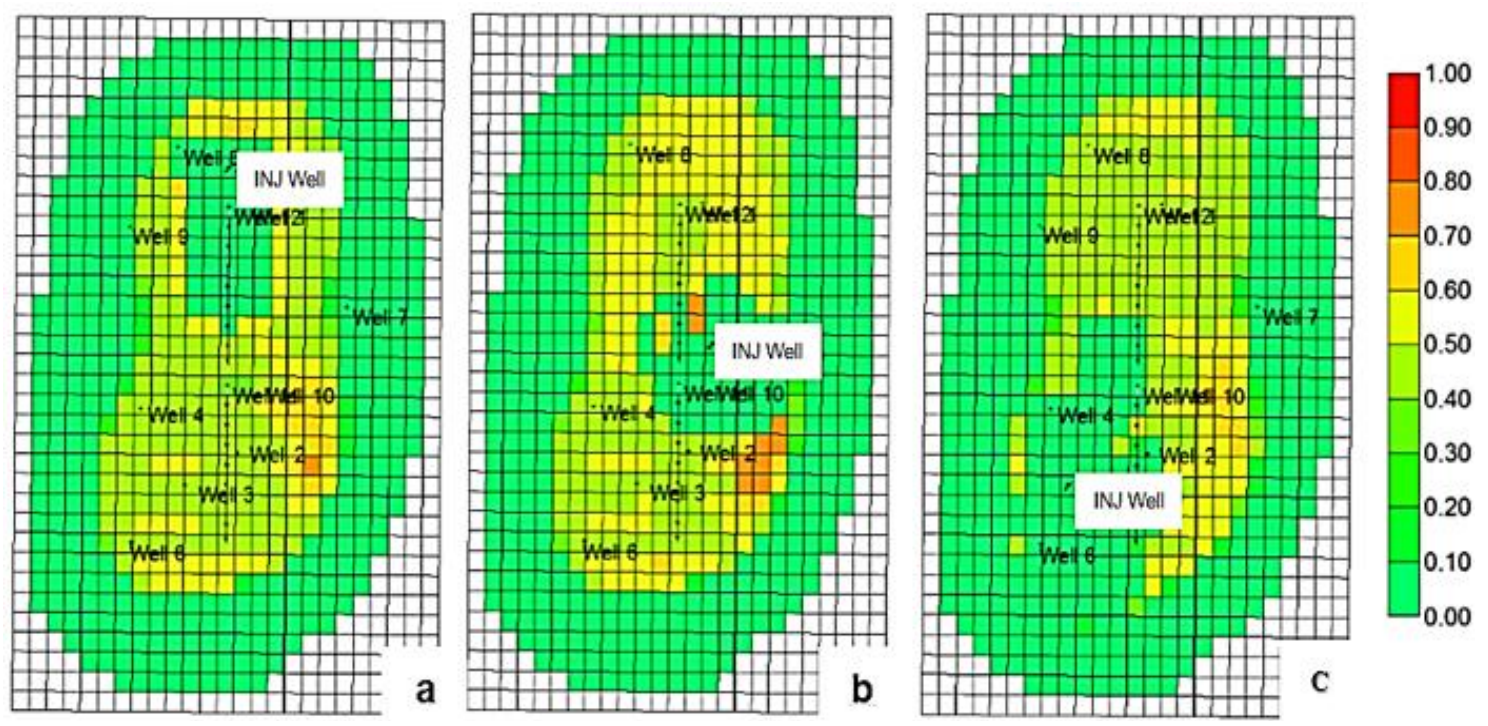

Figure12. Oil saturations and location of injection wells: (a) North, (b) Middle, and (c) South.

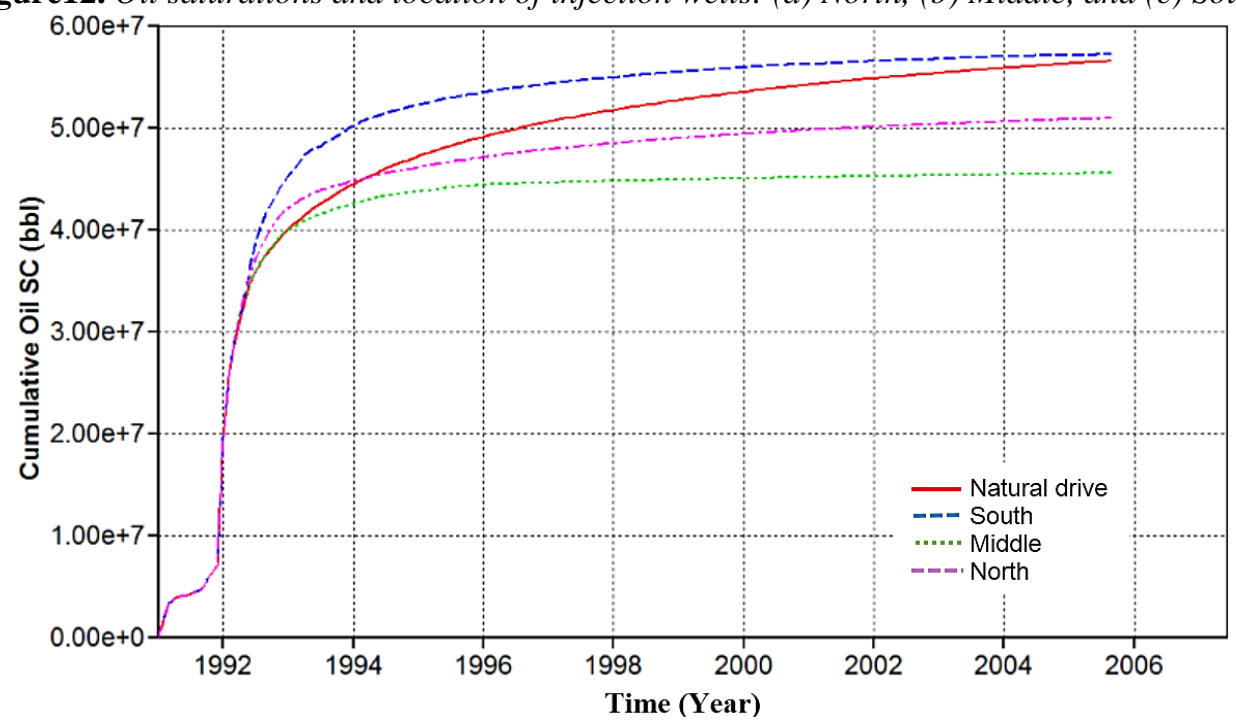

Figure13. Results of cumulative oil production of different locations of Injection Well

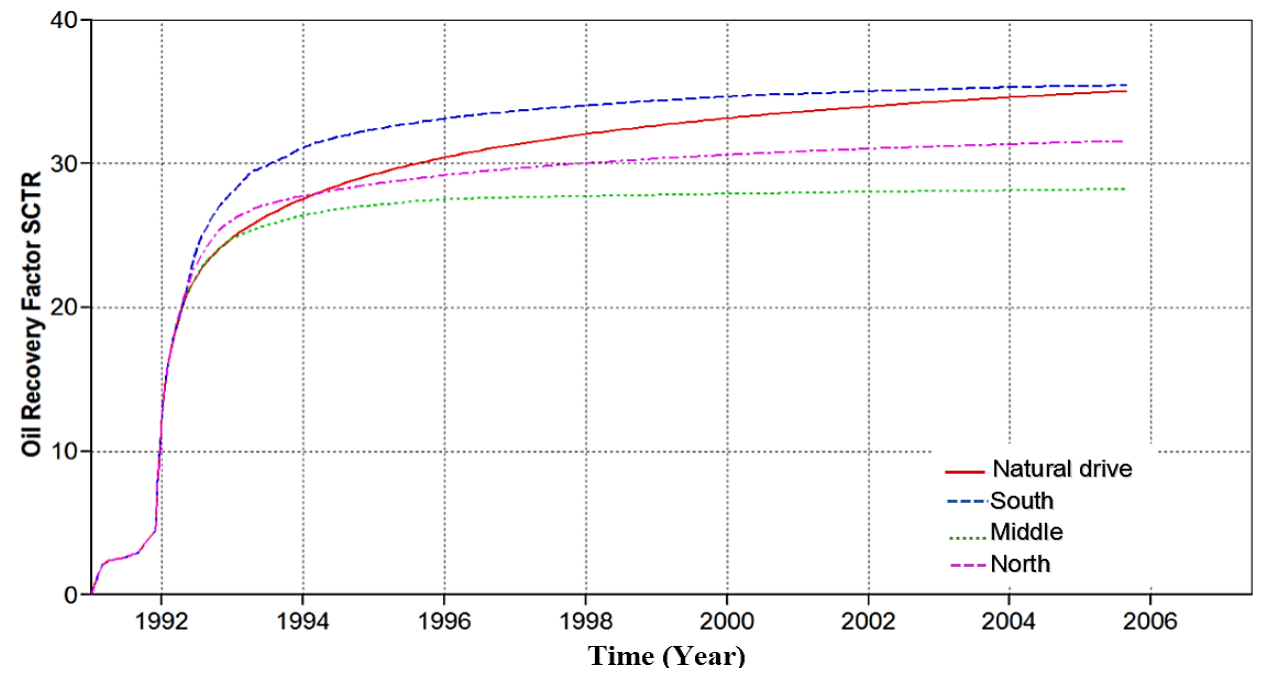

Figure14. Recovery factors of Injection wells location.

Therefore, it had a high cumulative oil production in the early dates of EOR production but after a year, it reached the abandonment pressure of the reservoir. Hence, WAG method can be applied to 
mitigate the effect of viscous fingering, improve the mobility ratio, and promoting better sweep efficiency in the reservoir. Moreover, the producers can be shut in for a period of time to allow the $\mathrm{CO}_{2}$ to mix efficiently with the oil before being produced again to regulate the flow.

On the other hand, the cost of drilling one injection well will be more cost effective compared to drilling of two or three injectors. Moreover, only slight improvement was observed on the reservoir performance in a short period of time if two injection wells are introduced; while a negative impact was seen on the reservoir performance in the long term. Therefore, the best number of injection well in this scenario would be one injector well.

\subsection{Run 4: Effect of Injection Pressure}

This simulation scenario has different injection pressures, which are 10, 20, 30, 40 and $50 \mathrm{MPa}$, respectively; at the optimum obtained conditions (south location and one injection well). Moreover, the injection pressure was manipulated with the injection rate kept constant at $30,000 \mathrm{~m}^{3}$. The injection was started on March 1992, which was the same date as other simulation runs. Therefore, five simulation runs with different injection pressures were conducted and the results are shown in (Figure 17), where the cumulative oil production was plotted against date in year.

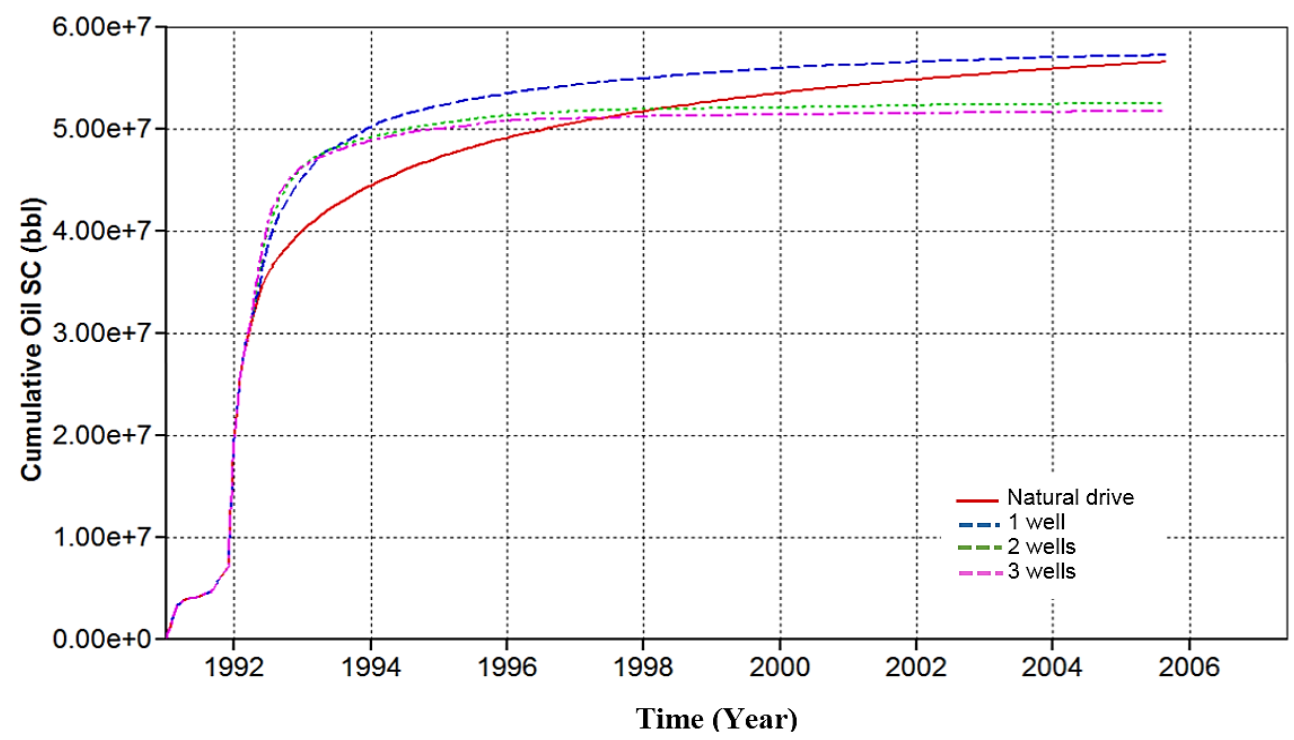

Figure15. Result of cumulative oil production with the number of injection wells.

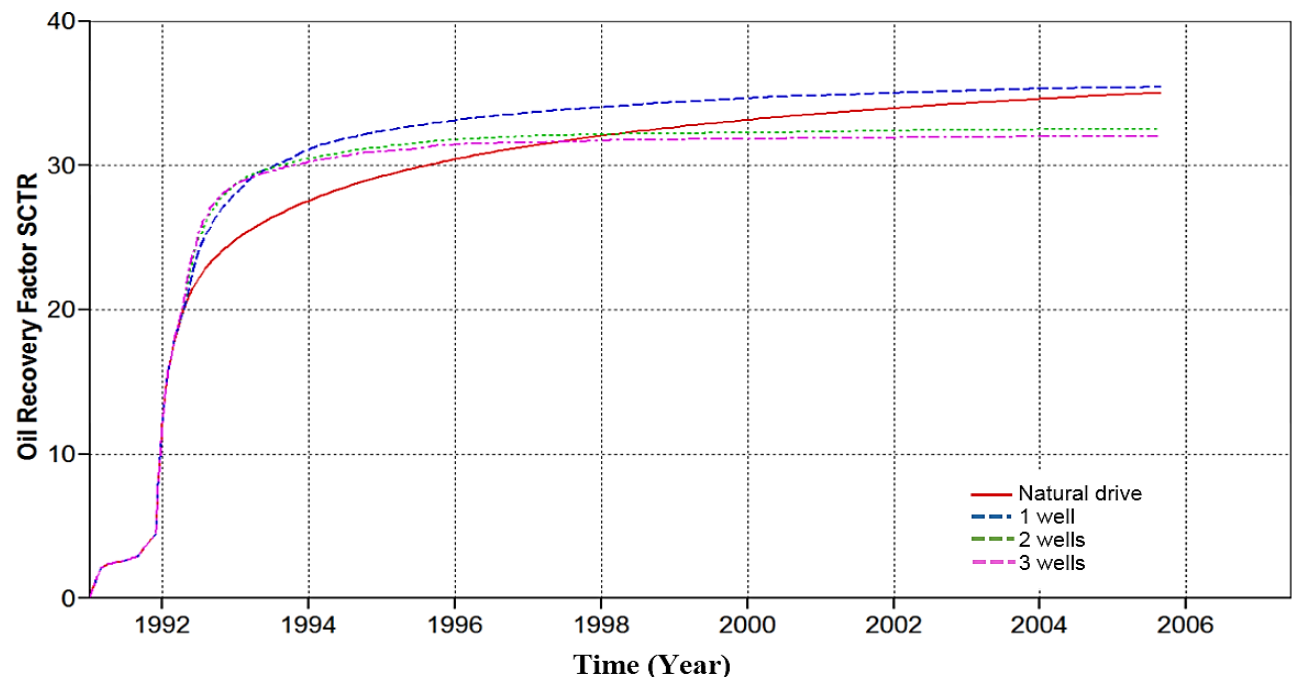

Figure16. Recovery factors of number of injection wells.

When the injection pressure was set 10 and $20 \mathrm{MPa}$, the cumulative oil production did not change with respect to the injection pressure. However, when the injection pressure was increased to $30 \mathrm{MPa}$, it resulted in a higher cumulative oil production with an additional oil recovery of $5 \%$ in the early stage of the production as shown in (Figure 18). This is because of increasing $\mathrm{CO}_{2}$ solubility in the oil at a higher pressure, which leads to a higher oil swelling effect. For that reason, it reduces the oil viscosity and leads to a better microscopic sweep efficiency. 
Moreover, it also was seen that when the injection pressure was increased up to 40 and $50 \mathrm{MPa}$, the cumulative production started to become lower than the cumulative oil production of $30 \mathrm{MPa}$. On the other hand, before 1994, it was observed that the cumulative oil production of 40 and $50 \mathrm{MPa}$ was higher than at 10 and $20 \mathrm{MPa}$ but not $30 \mathrm{MPa}$. Therefore, the viscous fingering might had taken place again due to the lower density and a high viscosity of $\mathrm{CO}_{2}$ relative to oil. This scenario usually causes gas cycling, which leads to poor utilization of $\mathrm{CO}_{2}$ injection in the reservoir. Therefore, the injection pressure is inversely proportional to the cumulative oil production.

Hence, to resolve the issue of viscous fingering, water can be injected with the $\mathrm{CO}_{2}$ in the alternating cycles known as WAG may reduce the effect of viscous fingering and promote better microscopic sweep efficiency. From this scenario, the best injection pressure to be utilized in this reservoir is 30 $\mathrm{MPa}$.

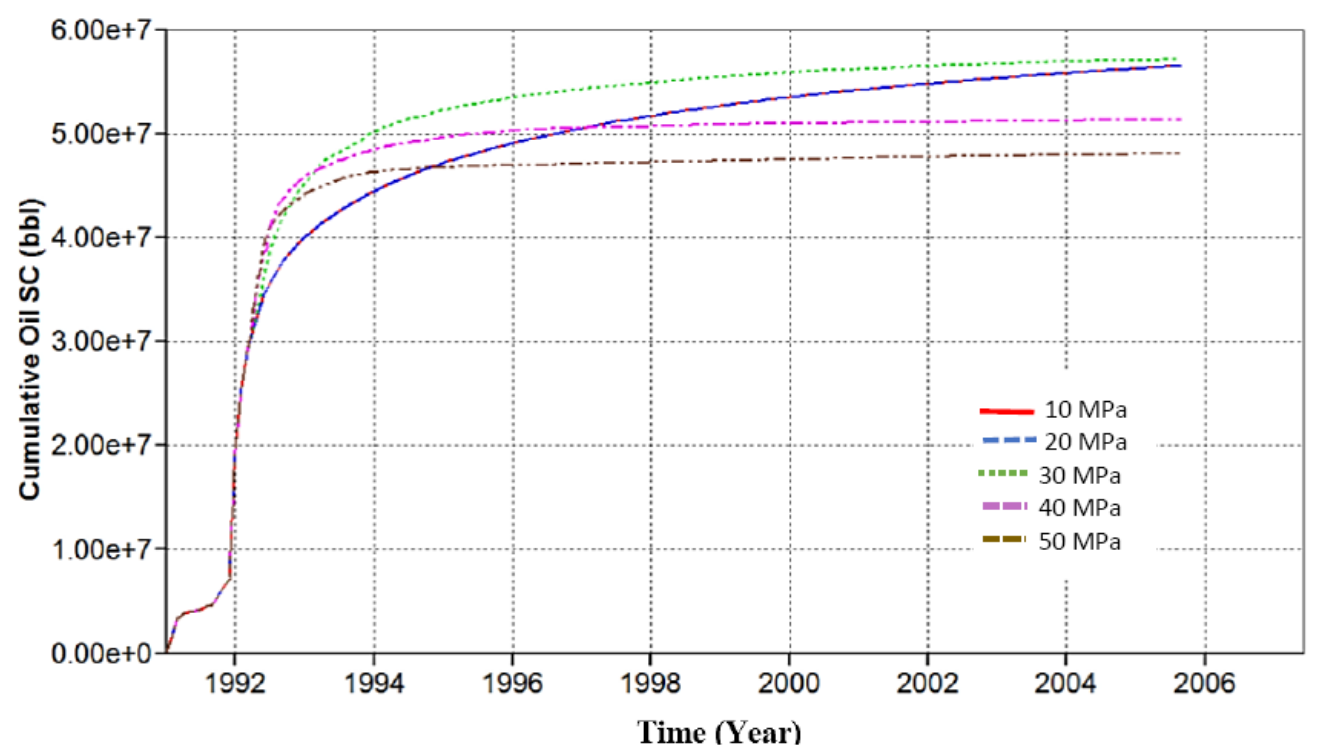

Figure17. Cumulative oil production of different injection pressures

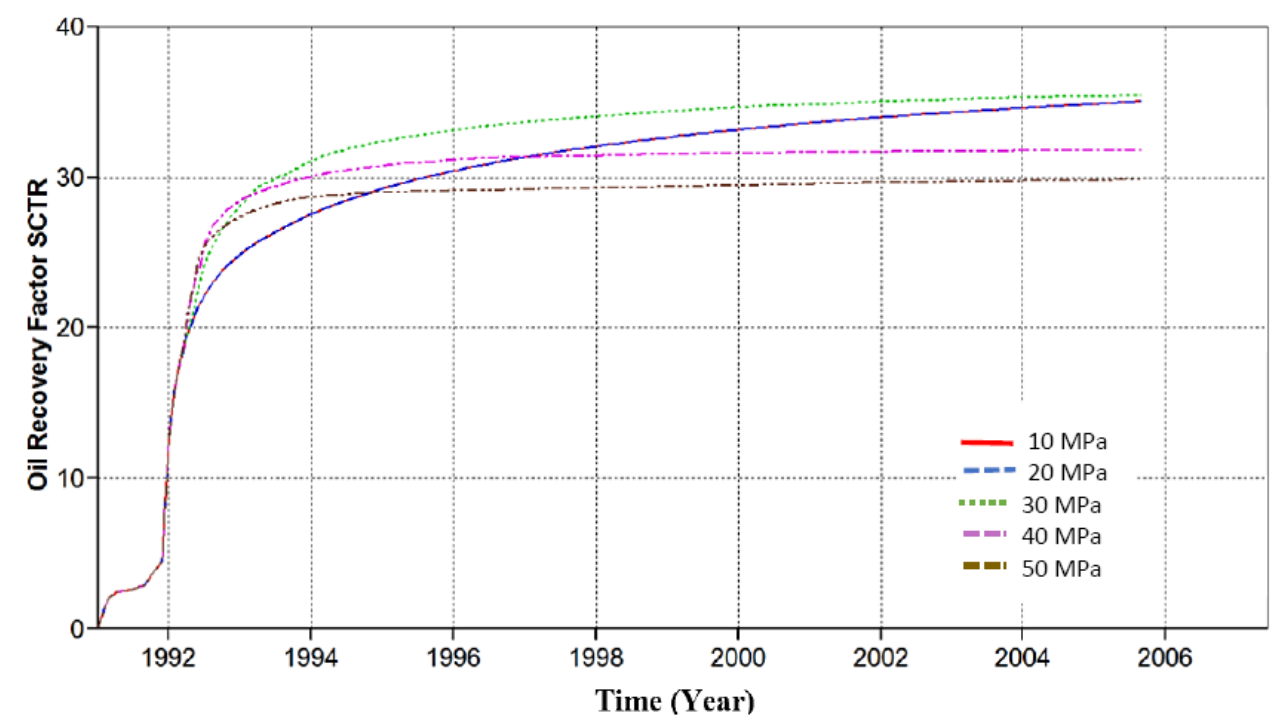

Figure18. Recovery factors of various injection pressures.

\section{Conclusions}

In this study, a compositional simulation model was built and run using CMG software where sub module GEM was utilized to study $\mathrm{CO}_{2}$ flooding potential as EOR method in an oil reservoir located east of Malaysia. A history matching study was performed to validate simulation results with the field data. From this research work, the following conclusions were drawn:

1. When horizontal production wells were drilled in which they had a significant impact on the oil recovery that increased to $35 \%$. Hence, the production was doubled the existing recovery of $18 \%$. 
2. When $\mathrm{CO}_{2}$ was injected at different periods (Run 1), the oil recovery was higher (4\%) than that of earlier $\mathrm{CO}_{2}$ injection run with only $1 \%$.

3. The injection well location was a significant factor which showed the south location is the most appropriate spot of injection with $4 \%$ oil recovery and $10 \%$ remaining oil saturations. Thus location enhances the oil recovery in a more efficient manner.

4. After implementing $\mathrm{CO}_{2}$ injection into various number of wells, it observed that one injection well had the best overall performance of oil recovery and cumulative with 5\% and 5 MMbblcompared to two and three injection wells.

5. When $\mathrm{CO}_{2}$ was injected at different pressures, the oil viscosity was reduced and improved the oil mobility where that seen at $30 \mathrm{MPa}$. As a result, the oil recovery was enhanced up to $5 \%$. In comparison with other pressure values which were not showing any significant improvement.

6. A well-defined production and injection scenario was a critical question for the optimization of $\mathrm{CO}_{2}$ as EORscheme. A field development strategy was initiated for this study by selecting the applicable conditions and locations for the injection wells in order to increase the oil recovery factor and cumulative.

\section{Conflict of Interest}

The authors have confirmed that there is no any conflict of interest.

\section{Acknowledgments}

The authors would like to acknowledge Computer Modelling Group Ltd Company for allowing us using CMG Software, which is donated for this study.

\section{Nomenclature}

\begin{tabular}{|l|l|}
\hline $\mathrm{CO}_{2}$ & $=$ Carbon Dioxide \\
\hline EOR & $=$ Enhanced Oil Recovery \\
\hline $\mathrm{CMG}$ & $=$ Computer Modelling Group \\
\hline OOIP & $=$ Original Oil in Place \\
\hline WAG & $=$ Water Alternation Gas \\
\hline IOR & $=$ Improved Oil Recovery \\
\hline $\mathrm{MMbbl}$ & $=$ Million Barrel \\
\hline $\mathrm{MPa}$ & $=$ Mega Pascal \\
\hline
\end{tabular}

\section{Appendix A:}

The material balance equation proposed by Havlena and Odeh (1963) was in the following form:

$F=N E_{0}+m N E_{g}+N E_{f, w}+W_{e} B_{w}$

Where:

$F=N_{p}\left[B_{o}+\left(R_{p}-R_{s}\right) B_{g}\right]+W_{p} B_{w}$

$E_{o}=\left(B_{o}-B_{o i}\right)+\left(R_{s i}-R_{s}\right) B_{g}$

$E_{f, w}=(1+m)+\left[\frac{\left(C_{w} S_{w c}-C_{f}\right) \Delta P}{1-S_{w c}}\right]$

$E_{g}=B_{o i}\left(\frac{B_{g}}{B_{g i}}-1\right)$

Therefore, to represent the material balance equation in fraction forms:

$1=\frac{N E_{0}}{F}+\frac{m N E_{g}}{F}+\frac{N E_{f, w}}{F}+\frac{W_{e} B_{w}}{F}$

Where:

$\frac{N E_{0}}{F} \quad-$ Represents Depletion Drive Index (DDI)

$\frac{m N E_{g}}{F}-$ Represents Segregation (Gas Cap) Drive Index (SDI) 
$\frac{N E_{f, w}}{F}-$ Represents Formation and Connate Water Compressibility Index (CDI)

$\frac{W_{e} B_{w}}{F}$ - Represents Water Drive Index (WDI)

The sum of the drive indices should be equal to one for the solution of material balance. Therefore, if the water drive index (WDI) has a fraction more than 0.4, it is a water drive reservoir with a bottom supported aquifer (Ahmed, 2005). The reservoir data is given as belowin SI unit:

TableA-1. Reservoir Data

\begin{tabular}{|c|c|}
\hline $\mathrm{V}_{\mathrm{r}}=3.395 \times 10^{8} \mathrm{~m}^{3}$ & $\Phi=0.1104$ \\
\hline $\mathrm{P}_{\mathrm{i}}=27,988 \mathrm{kPa}$ & $\mathrm{S}_{\mathrm{wc}}=0.2$ \\
\hline $\mathrm{P}_{\mathrm{ave}}=27,916 \mathrm{kPa}$ & $\mathrm{B}_{\mathrm{g}}=0.003874 \mathrm{~m}^{3} / \mathrm{m}^{3}$ \\
\hline $\mathrm{C}_{\mathrm{f}}=2 \times 10^{-5} \mathrm{kPa}^{-1}$ & $\mathrm{~N}_{\mathrm{p}}=751612 \mathrm{~m}^{3}$ \\
\hline $\mathrm{C}_{\mathrm{w}}=4.35 \times 10^{-7} \mathrm{kPa}^{-1}$ & $\mathrm{~W}_{\mathrm{p}}=148477 \mathrm{~m}^{3}$ \\
\hline $\mathrm{R}_{\mathrm{si}}=174.29 \mathrm{~m}^{3} / \mathrm{m}^{3}$ & $\mathrm{R}_{\mathrm{p}}=18.58 \mathrm{~m}^{3} / \mathrm{m}^{3}$ \\
\hline $\mathrm{R}_{\mathrm{s}}=173.74 \mathrm{~m}^{3} / \mathrm{m}^{3}$ & $\mathrm{~B}_{\mathrm{w}}=1 \mathrm{~m}^{3} / \mathrm{m}^{3}$ \\
\hline $\mathrm{B}_{\mathrm{oi}}=1.4762 \mathrm{~m}^{3} / \mathrm{m}^{3}$ & $\mathrm{~B}_{\mathrm{o}}=1.4747 \mathrm{~m}^{3} / \mathrm{m}^{3}$ \\
\hline
\end{tabular}

Since there is no gas cap in the reservoir, $\mathrm{m}=0$. Therefore, simplifying equation 1 and 2 ,

$F=N E_{0}+N E_{f, w}+W_{e} B_{w}$

$1=\frac{N E_{0}}{F}+\frac{N E_{f, w}}{F}+\frac{W_{e} B_{w}}{F}$

Oil Initial in Place (OIIP), $\mathrm{N}$ :

$N=\frac{V \emptyset\left(1-S_{w c}\right)}{B_{o i}}=20312044 \mathrm{~m}^{3}$

$F=N_{p}\left[B_{o}+\left(R_{p}-R_{s}\right) B_{g}\right]+W_{p} B_{w}=805093 m^{3}$

$E_{o}=\left(B_{o}-B_{o i}\right)+\left(R_{s i}-R_{s}\right) B_{g}=6.307 \times 10^{-4} \frac{m^{3}}{m^{3}}$

$E_{f, w}=(1+m)+\left[\frac{\left(C_{w} S_{w c}-C_{f}\right) \Delta P}{1-S_{w c}}\right]=2.6687 \times 10^{-3} \frac{m^{3}}{m^{3}}$

Substitute all the values of $\mathrm{F}, \mathrm{N}, \mathrm{E}_{\mathrm{o}}, \mathrm{E}_{\mathrm{f}, \mathrm{w}}$ and $\mathrm{B}_{\mathrm{w}}$ into the equation 3:

$F=N E_{0}+N E_{f, w}+W_{e} B_{w}$

$W_{e}=738075 \mathrm{~m}^{3}$

Hence, substitute the values of $\mathrm{F}, \mathrm{N}, \mathrm{E}_{\mathrm{o}}, \mathrm{E}_{\mathrm{f}, \mathrm{w}}, \mathrm{B}_{\mathrm{w}}$ and $\mathrm{W}_{\mathrm{e}}$ into equation 4 :

$1=\frac{N E_{0}}{F}+\frac{m N E_{g}}{F}+\frac{N E_{f, w}}{F}+\frac{W_{e} B_{w}}{F}$

$1=0.067+0.0159+0.9177$

The above calculations show that $6.7 \%$ was obtained by depletion drive, $91.77 \%$ by water drive and only $1.59 \%$ by connate water and rock expansion. The result shows that the water drive was the main driving mechanism. Therefore, the reservoir pressure is mainly maintained by the water aquifer. In addition, the water drive index of 0.9177 indicates a very strong bottom supported aquifer.

\section{Appendix B:}
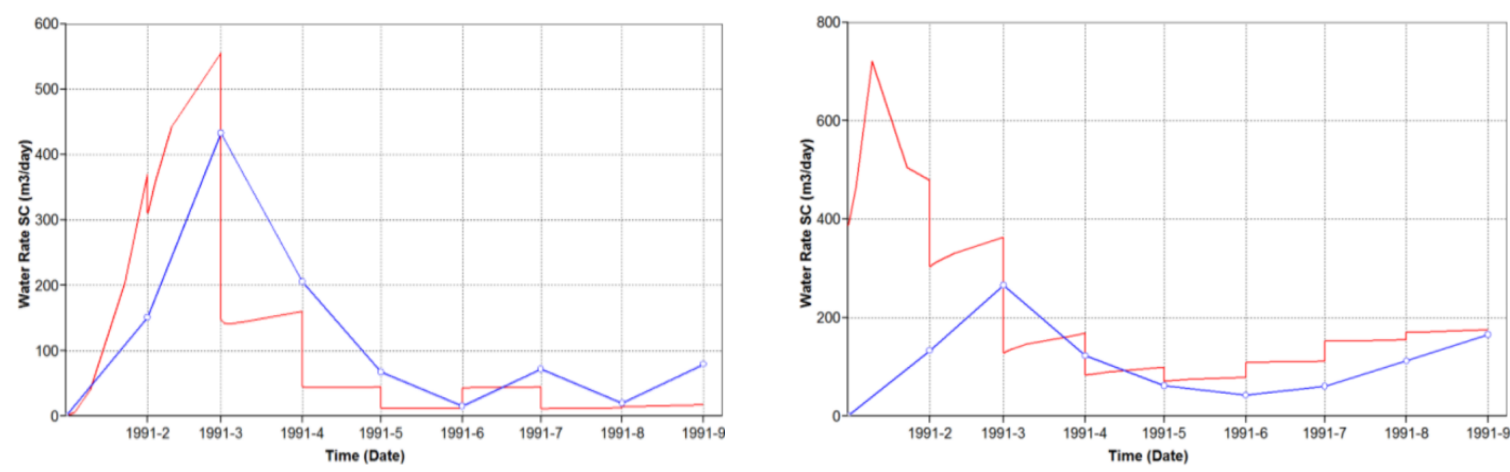

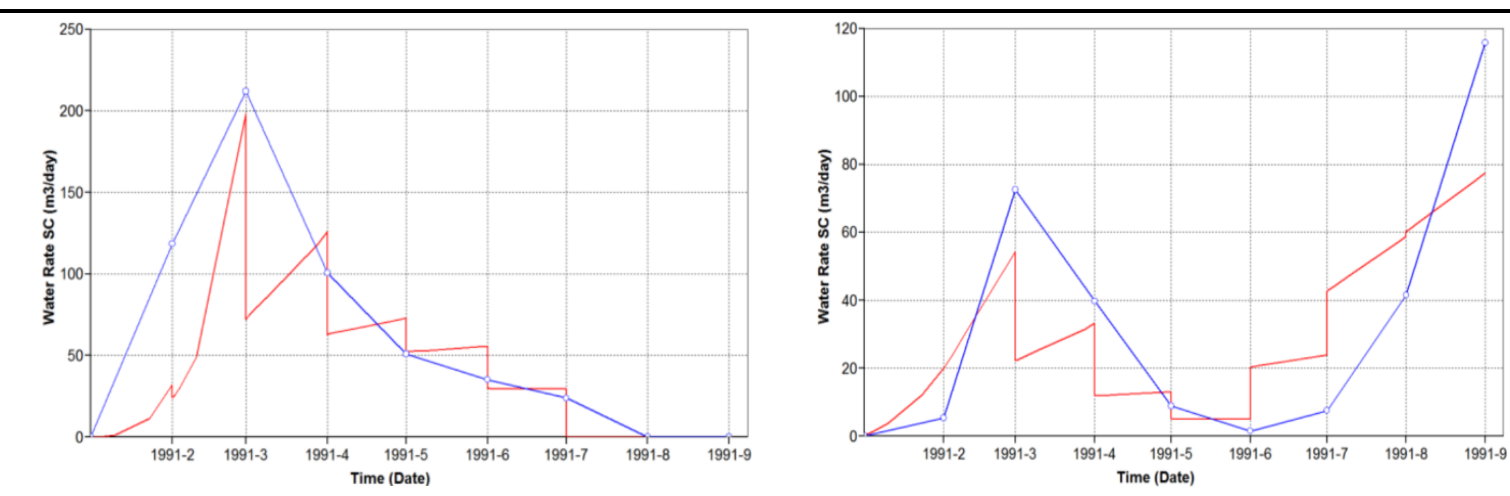

Figure3. Water production history matching.
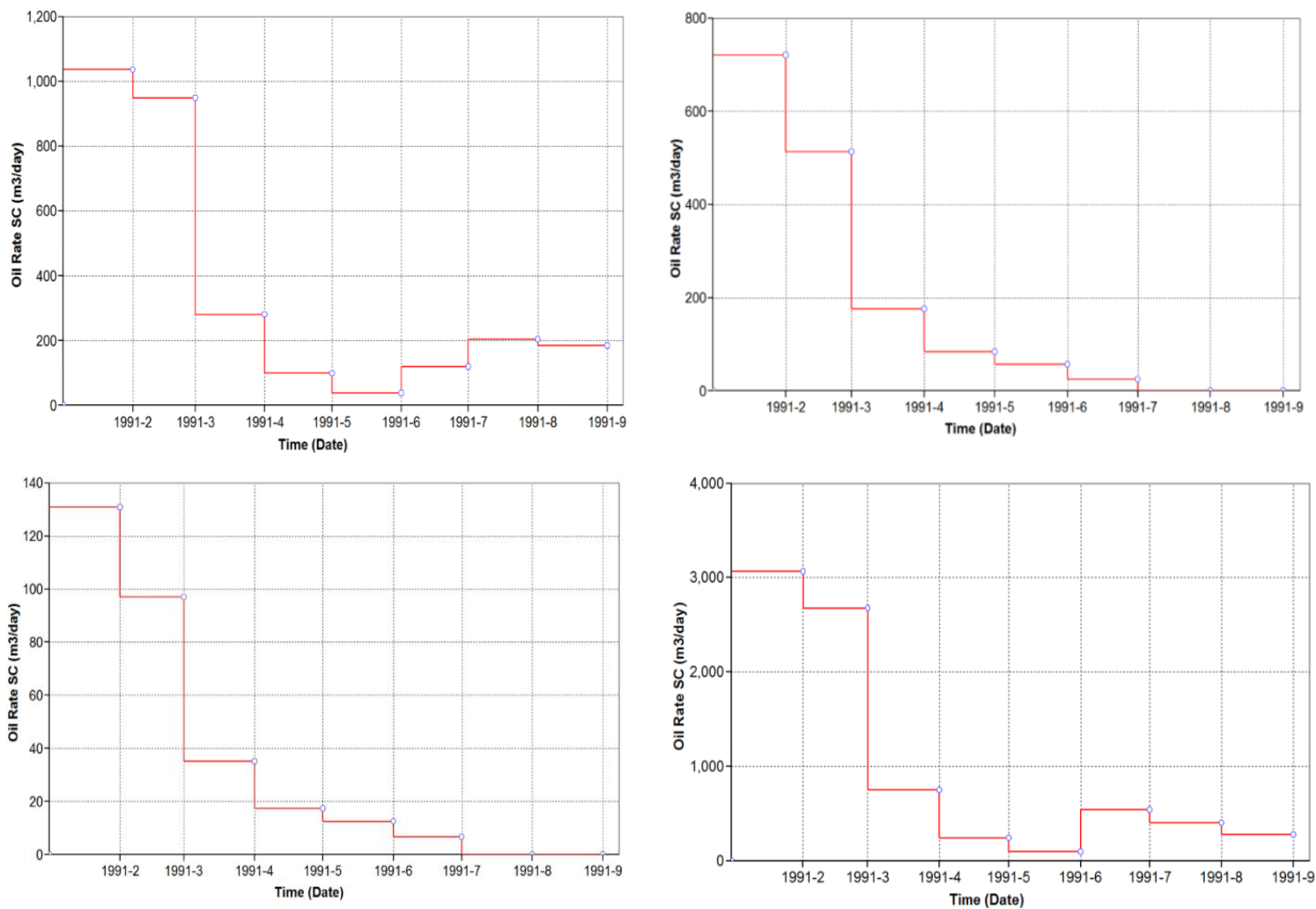

Figure4. Oil production history matching

\section{REFERENCES}

[1] Hisham B. M., Ian H. S.and Mian U. S. (2016). Evaluate Horizontal Well Production Performance in Heavy Oil Reservoirs, ARPN Journal of Engineering and Applied Sciences, VOL. 11, NO. 24, DECEMBER.

[2] Ahmed, T. P. (2005). Advanced Reservoir Engineering. Oxford, UK: Elsevier Inc.

[3] lvarado, V. a. (2010). Enhanced Oil Recovery: An Update Review. Energies Journal , 47.

[4] Mathiassen, O. M. (2003). CO2 as Injection Gas for Enhanced Oil Recovery and Estimation of the Potential on the Norwegian Continental Shelf. Norwegin: Norwegian University of Science and Technology.

[5] Meyer, J. P. (2009). Summary of Carbon Dioxide Enhanced Oil Recovery $\left(\mathrm{CO}_{2} \mathrm{EOR}\right)$ Injection Well Technology. Texas: American Petroleum Institute.

[6] Taber, J. (1997). EOR Screening Criteria Revisited-Part 1: Introduction to Screening Criteria and Enhanced Recovery Field Projects. Mexico: New Mexico Petroleum Recovery Research Center.

[7] Amao, A. M. (2009). Permian Basin: Historical Review of CO2 EOR Processes, Current Challenges and Improved Optimization Possibilities. Internation Symposium of the Society of Core Analysts , 6. 
[8] Zakirov, I. I.-B. (2012). Water Injection Patterns Optimization Approach on High-Viscous Oil in Russkoye Field. Society of Petroleum Engineers, 13.

[9] Suman, Y. K.-K. (2013). Investigating Improved Oil Recovery in Heavy Oil Reservoirs. World Journal of Engineering and Technology , 9.

\section{AUTHORS' BIOGRAPHY}

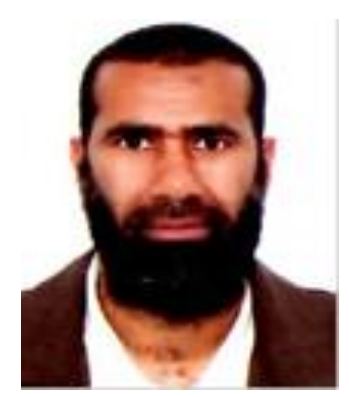

Hisham Khaled Ben Mahmud, has achieved Bachelor, Master and PhD degree in Chemical Engineering from Tripoli University, Sydney University and Curtin University, Australia, respectively. Also I have gained Graduate Diploma in oil and gas from University of Western Australia (UWA). I have expertise in modelling multiphase flow into subsea systems such as pipeline, jumper, riser evaluating pressure drop, and liquid holdup. Also optimize the risk of hydrate blockages into bend pipes. Recently I have involved into upstream research area including reservoir matrix acidizing, experimentally injecting a fluid (acid) into a core sample (sandstone or carbonate) to improve reservoir properties (porosity, permeability) observing wormhole and precipitation reaction. Another area I involve in is enhanced oil recovery (EOR) in brown oil field using different injecting fluids $(\mathrm{CO} 2$, water, polymer, surfactant) or modify production wells in order to improve hydrocarbon fluid recovery by minimizing oil wettability, surface tension and increase contact area.

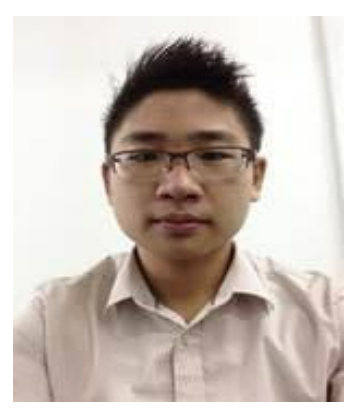

Ian Chang Huan Sheng, Obtained First Class Honors in Petroleum Engineering (Curtin University, Malaysia) 2015. I was President of SPE Student Chapter Curtin University Sarawak Malaysia and President and CoFounder of IEM Student Section Curtin University, Malaysia. Currently, I work with Shell Sabah as Reservoir Engineer. 